\title{
Long-term effects of surgical ventricular restoration with additional restrictive mitral annuloplasty and/or coronary artery bypass grafting on left ventricular function: Six-month follow-up by pressure-volume loops
}

\author{
Ellen A. ten Brinke, MD, ${ }^{a}$ Robert J. Klautz, MD, PhD, ${ }^{b}$ Sven A. Tulner, MD, PhD, ${ }^{a}$ \\ Harriette F. Verwey, MD, PhD, ${ }^{a}$ Jeroen J. Bax, MD, PhD, ${ }^{\text {a }}$ Martin J. Schalij, MD, PhD, ${ }^{a}$ Ernst E. van der \\ Wall, MD, PhD, ${ }^{\mathrm{a}}$ Michel I. Versteegh, MD, ${ }^{\mathrm{b}}$ Robert A. Dion, MD, PhD, ${ }^{\mathrm{b}}$ and Paul Steendijk, $\mathrm{PhD}^{\mathrm{a}}$
}

Objectives: Previous studies demonstrated beneficial short-term effects of surgical ventricular restoration on mechanical dyssynchrony and left ventricular function and improved midterm and long-term clinical parameters. However, long-term effects on systolic and diastolic left ventricular function are still largely unknown.

\begin{abstract}
Methods: We studied 9 patients with ischemic dilated cardiomyopathy who underwent surgical ventricular restoration with additional restrictive mitral annuloplasty and/or coronary artery bypass grafting. Invasive hemodynamic measurements by conductance catheter (pressure-volume loops) were obtained before and 6 months after surgery. In addition, New York Heart Association classification, quality-of-life score, and 6-minute hallwalk test were assessed.
\end{abstract}

Results: At 6 months' follow-up, all patients were alive and clinically in improved condition: New York Heart Association class from $3.3 \pm 0.5$ to $1.4 \pm 0.7$, quality-of-life score from $46 \pm 22$ to $15 \pm 15$, and 6-minute hallwalk test from $302 \pm 123$ to $444 \pm 78 \mathrm{~m}$ (all $P<.01$ ). Hemodynamic data showed improved cardiac output $(4.8 \pm$ 1.4 to $5.6 \pm 1.1 \mathrm{~L} / \mathrm{min})$, stroke work $(6.5 \pm 1.9$ to $7.1 \pm 1.4 \mathrm{~mm} \mathrm{Hg} \cdot \mathrm{L} ; P=.05)$, and left ventricular ejection fraction $(36 \% \pm 10 \%$ to $46 \% \pm 10 \% ; P<.001)$. Left ventricular surgical remodeling was sustained at 6 months: end-diastolic volume decreased from $246 \pm 70$ to $180 \pm 48 \mathrm{~mL}$ and end-systolic volume from $173 \pm 77$ to $103 \pm$ $40 \mathrm{~mL}$ (both $P<.001)$. Left ventricular dyssynchrony decreased from $29 \% \pm 6 \%$ to $26 \% \pm 3 \%(P<.001)$ and ineffective internal flow fraction decreased from $58 \% \pm 30 \%$ to $42 \% \pm 18 \%(P<.005)$. Early relaxation (Tau, minimal rate of pressure change) was unchanged, but diastolic stiffness constant increased from $0.012 \pm$ 0.003 to $0.023 \pm 0.007 \mathrm{~mL}^{-1}(P<.001)$.

Conclusions: Surgical ventricular restoration with additional restrictive mitral annuloplasty and/or coronary artery bypass grafting leads to sustained left ventricular volume reduction at 6 months' follow-up. We observed improved systolic function and unchanged early diastolic function but impaired passive diastolic properties. Clinical improvement, supported by decreased New York Heart Association class, improved quality-of-life score, and improved 6-minute hall-walk test may be related to improved systolic function, reduced mechanical dyssynchrony, and reduced wall stress. (J Thorac Cardiovasc Surg 2010;140:1338-44)

Chronic heart failure is a leading cause of morbidity and mortality. Most affected patients have an ischemic etiology, and in case of anteroseptal infarction, left ventricular (LV) aneurysm

\footnotetext{
From the Departments of Cardiology ${ }^{\mathrm{a}}$ and Cardiothoracic Surgery, ${ }^{\mathrm{b}}$ Leiden University Medical Center, Leiden, The Netherlands.

This study was supported by a grant from the Netherlands Heart Foundation (NHS2006B086)

Disclosures: Jeroen J. Bax receives research grants from GE Healthcare, BMS Medical Imaging, St Jude Medical, Inc, Medtronic, Boston Scientific, Biotronik, and Edwards Lifesciences. Martin J. Schalij receives research grants from Boston Scientific, Medtronic, and Biotronik. The authors have no conflicts of interest to disclose. Received for publication Nov 6, 2009; revisions received Jan 4, 2010; accepted for publication Jan 18, 2010; available ahead of print April 12, 2010.

Address for reprints: Paul Steendijk, PhD, Departments of Cardiology and Cardiothoracic Surgery, Leiden University Medical Center, Albinusdreef 2, PO Box 9600, 2300RC, Leiden, The Netherlands (E-mail: p.steendijk@lumc.nl).

0022-5223/\$36.00

Copyright (C) 2010 by The American Association for Thoracic Surgery doi:10.1016/j.jtcvs.2010.01.029
}

is a frequent complication. Abnormal LV geometry and dyscoordinate wall motion may cause a highly inefficient pump function. Ultimately, adverse effects on the remote myocardium, which is exposed to increased workload at enhanced wall stress despite compensatory hypertrophy, may lead to cardiac failure. Patients with LV aneurysm often remain symptomatic despite optimal medical treatment, and surgery may be indicated. Surgical ventricular restoration (SVR) by means of endoventricular circular patch plasty is increasingly performed. With this procedure, akinetic or dyskinetic sections of the anterior wall and septum are excluded to normalize cavity volume and to reshape an elliptical LV, using a Dacron patch to establish wall continuity and ensure adequate residual volume. Studies have shown that SVR is effective and relatively safe with a favorable 5 -year outcome, ${ }^{1,2}$ although the additional effect of SVR to coronary artery bypass grafting 


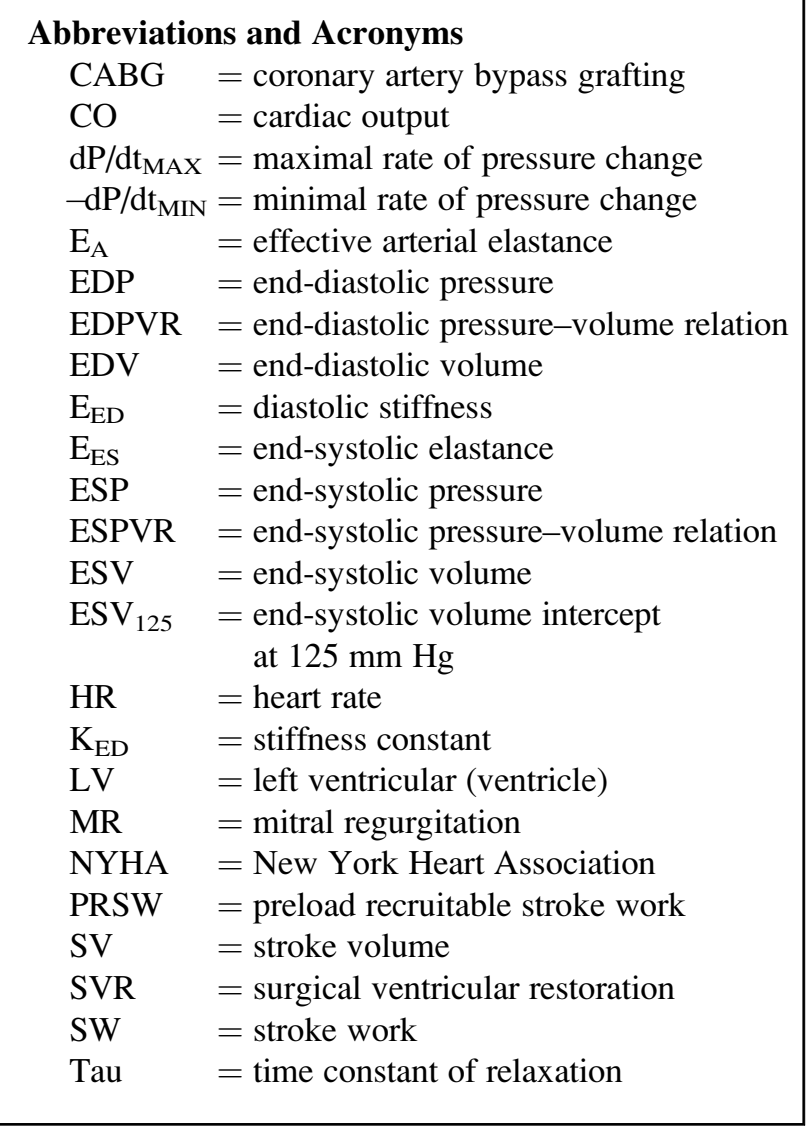

(CABG) remains debated. ${ }^{3,4} \mathrm{SVR}$ is also frequently combined with mitral valve repair, and the impact of that procedure in patients with heart failure has been the subject of several recent studies. ${ }^{5}$ Recent hemodynamic studies demonstrated that SVR may acutely reduce LV mechanical dyssynchrony and wall stress and improve LV systolic function. ${ }^{6}$ However, as predicted by theoretical studies, SVR may be associated with diastolic dysfunction limiting the overall beneficial effects on cardiac pump function. Adverse effects on diastolic function were previously demonstrated in the acute phase, ${ }^{6}$ but accurate long-term human data of the potentially differential effects of SVR on systolic and diastolic function are lacking. Therefore, we studied the long-term hemodynamic effects in patients with heart failure and ischemic dilated cardiomyopathy treated with SVR. Additional surgery included restrictive mitral annuloplasty and/or CABG. Global, systolic, and diastolic LV function were assessed invasively using conductance catheter-derived pressure-volume loops before surgery and at 6 months' follow-up.

\section{METHODS}

\section{Patients}

The study group consisted of 9 patients with ischemic dilated cardiomyopathy, New York Heart Association (NYHA) class III/IV, and LV ejection fraction less than $35 \%$ who underwent SVR. In 8 patients with moderateto-severe mitral regurgitation (MR grade $\geq 2$ ) additional restrictive mitral annuloplasty was performed. All patients underwent additional CABG (CABG, $\mathrm{n}=8)$ or had recent percutaneous coronary intervention $(\mathrm{n}=1)$. The protocol was approved by our institutional ethics committee and all patients gave informed consent. Patient characteristics, medication, and surgical data are summarized in Table 1.

\section{Study Protocol}

Baseline hemodynamic data were obtained during diagnostic catheterization, $25 \pm 18$ days before surgery, including thermodilution cardiac output, ventriculography, and coronary angiography. In addition, a 7F conductance catheter (CD-Leycom, Zoetermeer, The Netherlands) was placed in the LV via the femoral artery and a temporary pacing lead in the right atrium to obtain pressure-volume loops at fixed incremental (80, 100,120 beats/min) heart rates (HRs). LV volume was calibrated by thermodilution and hypertonic saline dilution. Data were acquired at least 1 minute after changing to a higher HR and periods of $\sim 20$ seconds were selected for offline analysis. All measurements were repeated after SVR during recatheterization at $6.5 \pm 0.8$ months' follow-up.

\section{Echocardiography}

Additional transesophageal echocardiography was performed within 5 days before surgery on patients with moderate-to-severe MR (grade $\geq 2$ ) seen on transthoracic echocardiography. Transesophageal echocardiography was done without general anesthesia to avoid underestimation of MR. Severity was graded semiquantitatively from color Doppler in conventional parasternal long-axis and apical 4-chamber images. Immediately after surgery, transesophageal echocardiography was repeated to exclude residual MR. At 6 months' follow-up, repeat transthoracic echocardiography assessed possible recurrent MR. All transthoracic echocardiography measurements were analyzed in random order by two independent observers without knowledge of the clinical status of the patient.

\section{Surgical Procedures}

Surgical procedures were performed using normothermic cardiopulmonary bypass with intermittent antegrade warm blood cardioplegia. After median sternotomy, patients underwent conventional CABG, with internal thoracic arteries when possible. Next, SVR was performed by an endoventricular circular patch plasty as previously described by Dor. ${ }^{7}$ In brief, the LV was opened through the infarcted area. An endocardial encircling suture (Fontan stitch) was placed at the transitional zone between scarred and normal tissue. A balloon containing $55 \mathrm{~mL}$ of saline per square meter of body surface area was introduced into the LV. The Fontan stitch was tightened to approximate the ventricular wall to the balloon. An oval Dacron patch was tailored and used to close the residual orifice. The excluded scar tissue was closed over the patch to ensure hemostasis. Care was taken to eliminate all septal scar and to delineate a new LV apex with the goal to restore the normal elliptical shape. After completion of the LV restoration, a stringent restrictive mitral annuloplasty ( 2 sizes smaller than the measured size) was performed by the atrial transseptal approach using a Carpentier-Edwards Physio ring (Edwards Lifesciences, Irvine, Calif).

\section{Data Analysis}

Hemodynamic indexes were calculated with custom-made software as the mean of all beats during a steady state period of $\sim 20$ seconds at each paced HR level. LV function was quantified by cardiac output (CO), LV ejection fraction, stroke volume (SV), end-diastolic and end-systolic volume (EDV, ESV) and pressure (EDP, ESP), and maximal and minimal rate of LV pressure change $\left(\mathrm{dP} / \mathrm{dt}_{\mathrm{MAX}},-\mathrm{dP} / \mathrm{dt}_{\mathrm{MIN}}\right)$. Stroke work (SW) was calculated as the pressure-volume loop area. Afterload (effective arterial elastance, $\mathrm{E}_{\mathrm{A}}$ ) was calculated as ESP/SV and mechanical efficiency (ME) as the ratio of SW and pressure-volume area (PVA): $\mathrm{ME}=\mathrm{SW} / \mathrm{PVA} .{ }^{8}$ To determine 
peak wall stress, we calculated time-varying wall stress from LV pressure and volume, $\mathrm{P}(\mathrm{t})$ and $\mathrm{V}(\mathrm{t})$, and $\mathrm{LV}$ mass as described by Arts and associates $^{9}: \mathrm{WS}(\mathrm{t})=\mathrm{P}(\mathrm{t}) \cdot(1+3 \cdot \mathrm{V}(\mathrm{t}) / \mathrm{LV}$ mass $) . \mathrm{LV}$ mass was based on diastolic posterior wall thickness derived from M-mode echocardiography. The endsystolic pressure-volume relation (ESPVR) was determined by single-beat analysis and quantified by its slope $\mathrm{E}_{\mathrm{ES}}$ (end-systolic elastance) and volume intercept at $125 \mathrm{~mm} \mathrm{Hg}\left(\mathrm{ESV}_{125}\right)$ as detailed elsewhere. ${ }^{10}$ The preload recruitable stroke work (PRSW) relation was determined as described by Lee and colleagues ${ }^{11}$ and characterized by slope $\mathrm{M}_{\mathrm{W}}$ and volume axes intercept $\mathrm{V}_{\mathrm{W}}$. The time constant of relaxation (Tau) was determined by phaseplot analysis. The end-diastolic pressure-volume relation (EDPVR) was derived from the filling phase trajectory of the pressure-volume loop including all data points between the moments of minimal pressure and maximal volume. $\mathrm{LV}$ diastolic stiffness $\left(\mathrm{E}_{\mathrm{ED}}\right)$ was determined as the linear slope of the EDPVR and the stiffness constant $\left(\mathrm{K}_{\mathrm{ED}}\right)$ from an exponential fit $\left(\mathrm{EDP}=\mathrm{A} \cdot \exp \left(\mathrm{K}_{\mathrm{ED}} \cdot \mathrm{EDV}\right) . \mathrm{EDPVR}\right.$ position was defined by the intercept at $18 \mathrm{~mm} \mathrm{Hg}\left(\mathrm{EDV}_{18}\right)$. LV mechanical dyssynchrony was determined from the segmental conductance signals. ${ }^{12}$ In addition, we calculated internal flow fraction to quantify the ineffective shifting of blood volume within the LV owing to nonuniform contraction and relaxation. ${ }^{12}$

\section{Statistical Analysis}

We used a linear mixed-effects model with patients included as random effects and conditions (baseline, 6 months' follow-up), pacing (80, 100 and 120 beats/min), and their interaction as fixed effects. This model accounts for correlation between repeated measurements. Data are presented as mean \pm SD. All analyses were performed using the statistical software program SPSS 16.0 (SPSS, Inc, Chicago, Ill). The authors had full access to the data and take responsibility for its integrity. All authors have read and agree to the manuscript as written.

\section{RESULTS}

Patient clinical characteristics and medication are reported in Table 1 . Note that in the present study we included a selected group of patients with complete hemodynamic follow-up by pressure-volume loops. In the associated 2-year interval, a total of 39 patients with NYHA class III/IV underwent SVR in our center. The operative mortality in this entire group was $10.3 \%$, and 6 months' survival was $87 \%$.

\section{Surgical and Clinical Data}

Surgery was associated with an aortic crossclamping time of $153 \pm 28$ minutes and a total cardiopulmonary bypass duration of $222 \pm 46$ minutes. In all cases, intraoperative transesophageal echocardiography excluded residual MR. Two patients needed an intra-aortic balloon pump to wean from $\mathrm{CPB}$ and 6 patients needed inotropic support (dobutamine $>2 \mu \mathrm{g} \cdot \mathrm{kg}^{-1} \cdot \min ^{-1}$ ) for more than 24 hours postoperatively. Hospital stay was $16 \pm 15$ days with an intensive care stay of $4 \pm 2$ days. All patients were discharged from the hospital in good clinical condition. At 6 months' follow-up, QRS duration was unchanged and the clinical status of the patients showed significant improvements (Table 1).

\section{Hemodynamic Data}

Hemodynamic data are summarized in Table 2. The statistical model tested differences between conditions (baseline, 6 months' follow-up), effect of HR (pacing), and the interac-
TABLE 1. Patient characteristics

\begin{tabular}{|c|c|c|}
\hline & Baseline & $\begin{array}{c}\text { Six months' } \\
\text { follow-up }\end{array}$ \\
\hline Patients (n) & 9 & \\
\hline Male (female) (n) & $7(2)$ & \\
\hline Age (y) & $62 \pm 6$ & \\
\hline Mean No. of stenosed coronary arteries & $2.0 \pm 1.0$ & \\
\hline QRS duration $(\mathrm{ms})$ & $109 \pm 19$ & $112 \pm 15$ \\
\hline \multicolumn{3}{|l|}{ Clinical characteristics } \\
\hline NYHA class & $3.3 \pm 0.5$ & $1.4 \pm 0.7^{*}$ \\
\hline 6-min hall-walk test (m) & $302 \pm 123$ & $444 \pm 78^{*}$ \\
\hline Quality-of-life score & $46 \pm 22$ & $15 \pm 15^{*}$ \\
\hline \multicolumn{3}{|l|}{ Medication } \\
\hline Diuretics & $6(67 \%)$ & $7(78 \%)$ \\
\hline Beta-blockers & $7(78 \%)$ & $6(67 \%)$ \\
\hline ACE inhibitors/AT antagonists & $8(89 \%)$ & $6(67 \%)$ \\
\hline Cholesterol inhibitors & $8(89 \%)$ & $8(89 \%)$ \\
\hline Vasodilators & $2(22 \%)$ & $1(11 \%)$ \\
\hline Aspirin/anticoagulants & $8(89 \%)$ & $6(67 \%)$ \\
\hline \multicolumn{3}{|l|}{ Surgical data } \\
\hline \multicolumn{3}{|l|}{ Surgical intervention } \\
\hline $\mathrm{SVR}+\mathrm{RMA}+\mathrm{CABG}$ & $7(78 \%)$ & \\
\hline SVR + RMA & $1(11 \%)$ & \\
\hline $\mathrm{SVR}+\mathrm{CABG}$ & $1(11 \%)$ & \\
\hline Ring size (RMA) & $25 \pm 1$ & \\
\hline Mitral regurgitation grade & $2.0 \pm 1.2$ & $0.3 \pm 0.5^{*}$ \\
\hline No. of distal anastomoses & $3 \pm 1$ & \\
\hline Cardiopulmonary bypass (min) & $222 \pm 46$ & \\
\hline Aorta crossclamping (min) & $153 \pm 28$ & \\
\hline Intensive care unit stay (d) & $4 \pm 2$ & \\
\hline Hospital stay (d) & $16 \pm 5$ & \\
\hline Intra-aortic balloon pump & $2(22 \%)$ & \\
\hline Inotropic support $\dagger>24 \mathrm{~h}$ & $6(66 \%)$ & \\
\hline
\end{tabular}

NYHA, New York Heart Association; $A C E$, angiotensin-converting enzyme; $A T$, angiotensin; SVR, surgical ventricular restoration; $R M A$, restrictive mitral annuloplasty; $C A B G$, coronary artery bypass grafting. Data are presented as number of patients involved and percent of the total group or as mean $\pm \mathrm{SD} . * P<.01$. †Dobutamine $>2 \mu \mathrm{g} \cdot \mathrm{kg}^{-1} \cdot \mathrm{min}^{-1}$.

tion between conditions and pacing. The latter would indicate whether effects of pacing were different between both conditions; however, none of the variables showed significant interaction. At follow-up, global LV function was improved as evidenced by significantly increased SW $(P=.05)$, a tendency for increased CO and SV $(P=.09$, $P=.06)$, and reduced peak wall stress $(P<.001)$. ESV and EDV were significantly reduced (both $P<.001$ ) with respectively $-40 \%$ and $-27 \%$ (at 80 beats $/ \mathrm{min}$ ), indicating substantial persistent reverse LV remodeling. The significant increase in SW combined with unchanged pressurevolume area resulted in an improved mechanical efficiency, which however did not reach statistical significance $(P=.113)$. Systolic function was improved as evidenced by a significantly increased slope and leftward shift of the PRSW relation $(P=.004, P<.001)$. Furthermore, we observed an increased LV ejection fraction and reduced $\mathrm{ESV}_{125}$ (both $P<.001$ ). $\mathrm{E}_{\mathrm{ES}}$ and the arterial/ventricular 
TABLE 2. Hemodynamics by pressure-volume loops at baseline and 6 months' follow-up after SVR

\begin{tabular}{|c|c|c|c|c|c|c|c|c|c|}
\hline & \multicolumn{3}{|c|}{ Baseline (beats/min) } & \multicolumn{3}{|c|}{ Six months' follow-up (beats/min) } & \multicolumn{3}{|c|}{$P$ values } \\
\hline & 80 & 100 & 120 & 80 & 100 & 120 & Condition & Pacing & Interaction \\
\hline \multicolumn{10}{|l|}{ General } \\
\hline HR (beats/min) & $79.5 \pm 2.9$ & $99.3 \pm 2.8$ & $121.9 \pm 2.6$ & $82.6 \pm 2.0$ & $101.7 \pm 1.4$ & $122.0 \pm 2.1$ & .003 & $<.001$ & .145 \\
\hline $\mathrm{CO}(\mathrm{L} / \mathrm{min})$ & $4.8 \pm 1.4$ & $4.7 \pm 2.3$ & $5.8 \pm 2.5$ & $5.6 \pm 1.1$ & $5.7 \pm 1.7$ & $5.3 \pm 2.3$ & .090 & .528 & .229 \\
\hline $\mathrm{SV}(\mathrm{mL})$ & $60 \pm 17$ & $47 \pm 23$ & $48 \pm 21$ & $68 \pm 13$ & $56 \pm 16$ & $43 \pm 19$ & .060 & $<.001$ & .271 \\
\hline $\mathrm{SW}(\mathrm{mm} \mathrm{Hg} \cdot \mathrm{L})$ & $6.5 \pm 1.9$ & $4.9 \pm 1.9$ & $4.9 \pm 2.1$ & $7.1 \pm 1.4$ & $6.0 \pm 1.1$ & $4.4 \pm 1.3$ & .050 & $<.001$ & .296 \\
\hline $\mathrm{E}_{\mathrm{A}}(\mathrm{mm} \mathrm{Hg} / \mathrm{mL})$ & $2.5 \pm 1.1$ & $3.9 \pm 2.3$ & $3.2 \pm 2.0$ & $2.0 \pm 0.7$ & $2.4 \pm 1.0$ & $3.3 \pm 1.6$ & .013 & .011 & .227 \\
\hline $\mathrm{E}_{\mathrm{A}} / \mathrm{E}_{\mathrm{ES}}$ & $2.24 \pm 1.17$ & $2.19 \pm 1.10$ & $2.60 \pm 1.36$ & $1.93 \pm 0.61$ & $2.16 \pm 0.66$ & $2.64 \pm 1.18$ & .163 & .045 & .793 \\
\hline ME & $0.49 \pm 0.12$ & $0.48 \pm 0.11$ & $0.45 \pm 0.15$ & $0.53 \pm 0.11$ & $0.51 \pm 0.10$ & $0.47 \pm 0.13$ & .113 & .078 & .964 \\
\hline PVA $(\mathrm{mm} \mathrm{Hg} \cdot \mathrm{L})$ & $14.1 \pm 6.6$ & $10.5 \pm 4.1$ & $11.0 \pm 3.3$ & $14.0 \pm 4.1$ & $12.1 \pm 3.1$ & $9.4 \pm 1.7$ & .763 & .003 & .511 \\
\hline PWS (mm Hg) & $431 \pm 177$ & $434 \pm 188$ & $465 \pm 240$ & $310 \pm 125$ & $307 \pm 118$ & $285 \pm 115$ & $<.001$ & .988 & .836 \\
\hline \multicolumn{10}{|l|}{ Systole } \\
\hline ESV (mL) & $173 \pm 77$ & $180 \pm 87$ & $184 \pm 93$ & $103 \pm 40$ & $105 \pm 44$ & $100 \pm 51$ & $<.001$ & .958 & .940 \\
\hline $\mathrm{ESP}(\mathrm{mm} \mathrm{Hg})$ & $133 \pm 32$ & $129 \pm 29$ & $122 \pm 25$ & $126 \pm 27$ & $123 \pm 25$ & $114 \pm 22$ & .088 & .140 & .958 \\
\hline $\mathrm{EF}(\%)$ & $36 \pm 10$ & $33 \pm 12$ & $32 \pm 11$ & $46 \pm 10$ & $42 \pm 12$ & $40 \pm 13$ & $<.001$ & .121 & .865 \\
\hline $\mathrm{dP} / \mathrm{dt}_{\mathrm{MAX}}(\mathrm{mm} \mathrm{Hg} / \mathrm{s})$ & $1291 \pm 274$ & $1368 \pm 261$ & $1424 \pm 324$ & $1291 \pm 225$ & $1384 \pm 209$ & $1384 \pm 224$ & .919 & .138 & .932 \\
\hline $\mathrm{E}_{\mathrm{ES}}(\mathrm{mm} \mathrm{Hg} / \mathrm{mL})$ & $1.2 \pm 0.6$ & $1.6 \pm 0.7$ & $1.5 \pm 0.7$ & $1.1 \pm 0.5$ & $1.2 \pm 0.4$ & $1.3 \pm 0.6$ & .087 & .378 & .792 \\
\hline $\mathrm{ESV}_{125}(\mathrm{~mL})$ & $165 \pm 96$ & $178 \pm 91$ & $187 \pm 101$ & $103 \pm 51$ & $111 \pm 57$ & $114 \pm 65$ & $<.001$ & .820 & .968 \\
\hline $\mathrm{M}_{\mathrm{W}}(\mathrm{mm} \mathrm{Hg})$ & $38 \pm 15$ & $29 \pm 15$ & $31 \pm 16$ & $48 \pm 7$ & $42 \pm 8$ & $32 \pm 11$ & .004 & .003 & .415 \\
\hline $\mathrm{V}_{\mathrm{W}}(\mathrm{mL})$ & $79 \pm 85$ & $76 \pm 91$ & $91 \pm 86$ & $29 \pm 51$ & $23 \pm 52$ & $9 \pm 54$ & $<.001$ & .772 & .802 \\
\hline \multicolumn{10}{|l|}{ Diastole } \\
\hline EDV (mL) & $246 \pm 70$ & $241 \pm 78$ & $243 \pm 86$ & $180 \pm 48$ & $171 \pm 49$ & $151 \pm 52$ & $<.001$ & .527 & .823 \\
\hline $\mathrm{EDP}(\mathrm{mm} \mathrm{Hg})$ & $19.8 \pm 8.6$ & $19.8 \pm 10.0$ & $19.7 \pm 9.3$ & $19.0 \pm 7.6$ & $15.6 \pm 8.1$ & $11.2 \pm 6.1$ & .021 & .118 & .262 \\
\hline$-\mathrm{dP} / \mathrm{dt}_{\mathrm{MIN}}(\mathrm{mm} \mathrm{Hg} / \mathrm{s})$ & $1166 \pm 238$ & $1180 \pm 213$ & $1180 \pm 232$ & $1187 \pm 287$ & $1211 \pm 250$ & $1180 \pm 229$ & .685 & .857 & .901 \\
\hline Tau (ms) & $80 \pm 14$ & $74 \pm 14$ & $67 \pm 16$ & $82 \pm 17$ & $76 \pm 14$ & $70 \pm 12$ & .351 & .003 & .895 \\
\hline $\mathrm{E}_{\mathrm{ED}}(\mathrm{mm} \mathrm{Hg} / \mathrm{mL})$ & $0.15 \pm 0.08$ & $0.14 \pm 0.08$ & $0.14 \pm 0.07$ & $0.24 \pm 0.11$ & $0.24 \pm 0.16$ & $0.23 \pm 0.18$ & $<.001$ & .821 & .960 \\
\hline $\mathrm{K}_{\mathrm{ED}}\left(\mathrm{mL}^{-1}\right)$ & $0.012 \pm 0.003$ & $0.010 \pm 0.006$ & $0.012 \pm 0.012$ & $0.023 \pm 0.007$ & $0.026 \pm 0.017$ & $0.035 \pm 0.032$ & $<.001$ & .434 & .530 \\
\hline $\mathrm{EDV}_{18}(\mathrm{~mL})$ & $261 \pm 93$ & $248 \pm 102$ & $266 \pm 115$ & $198 \pm 40$ & $190 \pm 56$ & $194 \pm 62$ & $<.001$ & .860 & .994 \\
\hline \multicolumn{10}{|l|}{ Dyssynchrony } \\
\hline DYS (\%) & $29.3 \pm 5.5$ & $29.4 \pm 6.1$ & $29.0 \pm 6.3$ & $26.3 \pm 3.4$ & $25.9 \pm 3.4$ & $25.4 \pm 2.7$ & $<.001$ & .800 & .912 \\
\hline IFF (\%) & $58 \pm 30$ & $62 \pm 35$ & $60 \pm 34$ & $42 \pm 18$ & $41 \pm 15$ & $39 \pm 15$ & .004 & .856 & .959 \\
\hline
\end{tabular}

$S V R$, Surgical ventricular restoration; $H R$, heart rate; $C O$, cardiac output; $S V$, stroke volume; $S W$, stroke work; $E_{A}$, arterial elastance; $E_{E S}$, end-systolic elastance (slope of ESPVR, end-systolic pressure-volume relation); $M E$, mechanical efficiency; $P V A$, pressure-volume area; $P W S$, peak wall stress; $E S V$, end-systolic volume; $E S P$, end-systolic pressure; $E F$, ejection fraction; $d P / d t_{M A X}$, maximal rate of pressure change; $E S V_{125}$, ESPVR intercept at $125 \mathrm{~mm} \mathrm{Hg} ; M_{W}$, slope of PRSW (preload recruitable stroke work relation); $V_{W}$, intercept of PRSW; $E D V$, end-diastolic volume; $E D P$, end-diastolic pressure; $-d P / d t_{M I N}$, minimum rate of pressure change; Tau, pressure relaxation time constant; $E_{E D}$, diastolic stiffness; $K_{E D}$, diastolic stiffness constant; $E D V_{18}$, intercept of EDPVR (end-diastolic pressure-volume relation) at $18 \mathrm{mmHg} ; D Y S$, mechanical dyssynchrony; $I F F$, internal flow fraction.

coupling ratio $\left(\mathrm{E}_{\mathrm{A}} / \mathrm{E}_{\mathrm{ES}}\right)$ did not change significantly, although afterload $\left(\mathrm{E}_{\mathrm{A}}\right)$ decreased significantly $(P=.013)$. Passive diastolic function showed impairment indicated by increased $\mathrm{E}_{\mathrm{ED}}$ and $\mathrm{K}_{\mathrm{ED}}$ (both $P<.001$ ). However, early, active relaxation indexed by Tau and $-\mathrm{dP} / \mathrm{dt}_{\mathrm{MIN}}$ was unaltered after SVR. EDV, calculated from the EDPVR at $18 \mathrm{~mm} \mathrm{Hg}$, was significantly reduced, reflecting lower operating volumes consistent with a leftward shift of the pressure-volume loop. Mechanical dyssynchrony and internal flow fraction were significantly $(P<.001, P=.004)$ reduced with $-10 \%$ and $-28 \%$, respectively, indicating substantially reduced dyssynchrony.

\section{DISCUSSION}

Previous research has shown that SVR is an effective therapy for patients with end-stage ischemic heart failure according to acceptable survivals, improved clinical perfor- mance, and sustained LV reverse remodeling diagnosed by echocardiography at midterm and long-term follow-up. ${ }^{13,14}$ Several previous studies examined the acute hemodynamic status after SVR showing the expected volume reductions, a decrease of mechanical dyssynchrony, improved systolic function, and impaired diastolic function, which effects however could be partly transient. ${ }^{6}$ The present study therefore was designed to analyze the chronic effects of SVR with additional restrictive mitral annuloplasty and/or CABG on several aspects of LV function, including chronotropic responses, at 6 months' follow-up. To our knowledge, long-term follow-up data, including invasive pressure-volume indices, have not been published previously for this patient group.

\section{Global LV Function}

Our results demonstrate sustained reverse LV remodeling with reduced $\operatorname{ESV}(-40 \%)$ and $\operatorname{EDV}(-27 \%)$ at 6 months' 
follow-up, exceeding the previously reported $\sim 25 \%$ acute volume reductions. ${ }^{6}$ In line with other studies, $\mathrm{CO}$ and $\mathrm{SV}$ showed a tendency to increase but did not reach statistical significance, whereas SW increased significantly after SVR. ${ }^{14,15}$ Afterload $\left(\mathrm{E}_{\mathrm{A}}\right)$ decreased significantly, which was also observed by Fantini and coworkers, ${ }^{16}$ whereas mechanical efficiency and pressure-volume area did not change significantly. Consequently, calculated wall stress, an important determinant of myocardial oxygen consumption, decreased substantially $(-28 \%)$, which may partly explain improved clinical performance. Our results regarding long-term relative volume reduction are in line with most previous studies at midterm follow-up (4-12 months). ${ }^{1,17-19}$ Likewise, the mean ESV index obtained at 6 months after SVR $\left(53 \pm 21 \mathrm{~mL} / \mathrm{m}^{2}\right)$ is in the same range as follow-up values reported in larger series by, for example, the RESTORE group ${ }^{1}\left(57 \pm 34 \mathrm{~mL} / \mathrm{m}^{2}\right)$, Dor and coworkers ${ }^{18}\left(51 \pm 18 \mathrm{~mL} / \mathrm{m}^{2}\right)$, and Di Donato and associates ${ }^{17}$ (average of 3 groups: $44 \pm 20 \mathrm{~mL} / \mathrm{m}^{2}$ ).

\section{Systolic LV Function}

Our data confirm previous findings regarding significantly improved LV ejection fraction after SVR. However, this may be partly due to reduced afterload and, more in general, the relevance of increased LV ejection fraction after SVR has been questioned. Therefore, additional systolic indices derived from load-independent pressure-volume relations ESPVR and PRSW were investigated. ESPVR showed a leftward shift evidenced by reduced $\mathrm{ESV}_{125}$, indicating improved systolic function, but the slope $\mathrm{E}_{\mathrm{ES}}$ was not significantly altered. $\mathrm{E}_{\mathrm{ES}}$ is often used to index systolic function; however, in case of regional dysfunction, the ESPVR may primarily show parallel shifts rather than a decreased slope presumably because at systolic pressure levels the aneurysm is very stiff. ${ }^{20}$ The PRSW relation showed a leftward shift (reduced intercept of PRSW) and increased slope of PRSW, both indicating improved systolic function. Although PRSW is predominantly a measure of systolic function, alterations in diastolic function also affect this relation. However, the negative effects on diastolic function in this case would tend to decrease the PRSW slope and thus partly mask even more positive systolic effects. The improved global systolic function presumably was related to improved functioning of the remote myocardium by reduced wall stress and reduced mechanical dyssynchrony.

\section{Diastolic Function}

Early active relaxation $\left(-\mathrm{dP} / \mathrm{dt}_{\mathrm{MIN}}\right.$, Tau) was unchanged after SVR, but passive diastolic stiffness was significantly increased. The fact that- $\mathrm{dP} / \mathrm{dt}_{\mathrm{MIN}}$ and Tau did not change, despite the substantial volume reduction, could result from negative effects due to a distortion of the normal myocardial fiber orientation. ${ }^{21}$ Apparently, increased diastolic stiffness observed acutely after $\mathrm{SVR}^{6}$ which, however, did not reach sig- nificance (pre-SVR: $\mathrm{K}_{\mathrm{ED}} 0.021 \pm 0.009 \mathrm{~mL}^{-1}$, post-SVR: $\left.\mathrm{K}_{\mathrm{ED}} 0.037 \pm 0.02 \mathrm{~mL}^{-1} ; P=.147\right)$ is still present at 6 months and thus not merely a transient effect of cardioplegic arrest. The significantly increased $\mathrm{K}_{\mathrm{ED}}$ in the present study cannot be directly compared with the results of the previous shortterm study performed in the operating room, ${ }^{6}$ because other effects related to the perioperative conditions may also play a role. ${ }^{9}$ To put these values into perspective, Kasner and associate $^{22}$ recently reported $\mathrm{K}_{\mathrm{ED}}$ to be approximately 0.010 $\mathrm{mL}^{-1}$ in normals and $0.029 \mathrm{~mL}^{-1}$ in patients with heart failure and normal ejection fraction, whereas in patients with hypertrophic obstructive cardiomyopathy a value of $0.025 \mathrm{~mL}^{-1}$ was found by Steendijk and coworkers. ${ }^{23}$ Thus, the baseline values for $\mathrm{K}_{\mathrm{ED}}$ in the present study of $0.012 \pm 0.003 \mathrm{~mL}^{-1}$ appear to be in the normal range, whereas $0.023 \pm 0.007 \mathrm{~mL}^{-1}$ observed 6 months after surgery is close to values observed in patient groups with diastolic dysfunction. A study by Zhang and colleagues ${ }^{24}$ in sheep also reported a tendency for increased diastolic stiffness up to 6 weeks after SVR. Furthermore, a few other studies have reported filling abnormalities after SVR and suggested that a marked reduction of LV size may result in a restrictive LV filling pattern. ${ }^{25,26}$ In our data set, we also found a correlation between the reduction in EDV and the increase in diastolic stiffness constant $\left(\% \Delta \mathrm{K}_{\mathrm{ED}}=41.9-3.0 \cdot \% \Delta \mathrm{EDV}, r^{2}=0.55, P<.01\right)$. This finding suggests that a restriction in the amount of $\mathrm{LV}$ volume reduction could be relevant to avoid diastolic dysfunction. However, the number of patients is too small to draw firm conclusions and further studies are needed to address this issue.

\section{Dyssynchrony}

Mechanical dyssynchrony is increasingly recognized as an important factor explaining LV dysfunction. Earlier studies $^{6}$ demonstrated an immediate improvement in dyssynchrony after SVR and the present data indicate persistent improvement at 6 months. The reduced dyssynchrony presumably underlies the improved systolic function, whereas the reduced intraventricular shifting of blood volume indexed by internal flow fraction will contribute to a more efficient pump function.

\section{HR Effect}

We performed measurements during pacing to exclude bias by altered HR and to investigate HR dependencies before and after SVR. Statistical analysis showed that CO tended $(P=.09)$ to be higher after SVR $(+18 \%$ at 80 beats/min) but the effect of pacing on $\mathrm{CO}$ was unaltered, indicating a remaining lack of chronotropic reserve. As shown in Figure 1, SV (width of pressure-volume loop) gradually decreased at higher HR, limiting the CO increase. Interestingly, it appeared that the reduction in SV was mainly due to an increase in ESV at baseline, but due to a decrease in EDV at 6 months' follow-up, suggesting that the resolved 

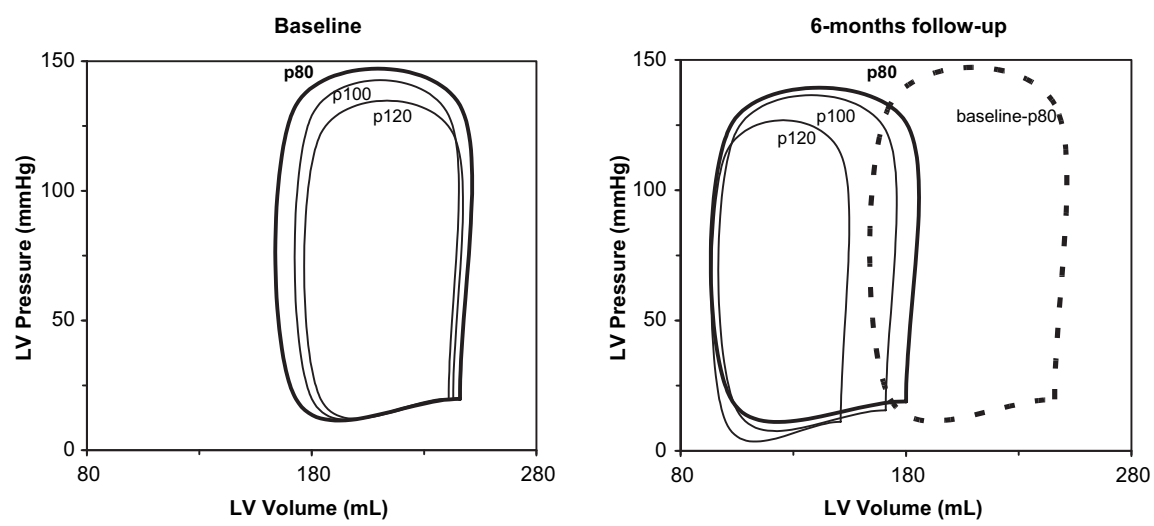

FIGURE 1. Schematic pressure-volume loops (based on mean end-diastolic and end-systolic pressures and volumes) at baseline (left panel) and 6 months after surgical ventricular restoration (SVR) (right panel). Loops are shown during pacing at 80, 100, and 120 beats/min (p80, p100, p120). Baseline p80 data are repeated in the right panel (dotted lines) to illustrate the substantial volume reduction induced by SVR. $L V$, Left ventricular.

contractile problem is partly biased by a filling abnormality. However, these pacing effects did not reach statistical significance and thus remain speculative. Interestingly, the response to pacing after SVR appears to be similar to that observed in patients with heart failure and preserved ejection fraction. ${ }^{27}$ It should be noted that increased HR by pacing only partly mimics the effects of exercise. Given the drop in EDP during pacing after SVR, sympathetic stimulation and volume recruitment during true exercise may lead to a more positive effect on $\mathrm{CO}$ by maintaining or even increasing normal filling pressures. ${ }^{27}$

\section{Additional Surgery}

In this study SVR was the primary indication for surgery, but additional CABG and/or restrictive mitral annuloplasty was performed in all patients. Therefore, the reported effects cannot be attributed to SVR alone. Revascularization has been shown to have beneficial effects in patients with ischemic dilated cardiomyopathy. ${ }^{28}$ Moreover, a recent randomized trial concluded that adding SVR to CABG in patients eligible for both procedures was not associated with greater clinical benefits than $\mathrm{CABG}$ alone, despite the fact that a larger reduction in ESV index was obtained ( $19 \%$ vs $6 \%$ ). ${ }^{3}$ However, this trial is currently strongly debated, in particular because the SVR-related volume reductions were much smaller than in other SVR trials (typically $\sim 40 \%$ ). ${ }^{29}$ Likewise, beneficial clinical effects and significant long-term volume reductions have been reported for restrictive mitral annuloplasty with or without $\mathrm{CABG} .{ }^{30,31}$ Pressure-volume loop studies in patients with restrictive mitral annuloplasty alone are in progress, but comparison with the present study will remain difficult because studies are not randomized and baseline characteristics of patients groups are different.

\section{Study Limitations}

In addition to the potentially confounding effects of additional surgery, the study is limited by a small sample size.
However, because we used each patient as his or her own control, statistical power was optimized. Moreover, we used invasive pressure-volume measurements, which are generally regarded as highly accurate and the gold standard for LV function assessments.

\section{CONCLUSIONS}

Our findings provide insight into the long-term effects of SVR on systolic and diastolic LV function and reveal that the clinical improvements presumably are due to improved systolic function and reduced dyssynchrony and wall stress, leading to more efficient global pump function. However, the surgical intervention may be associated with an adverse effect on diastolic function limiting its full potential

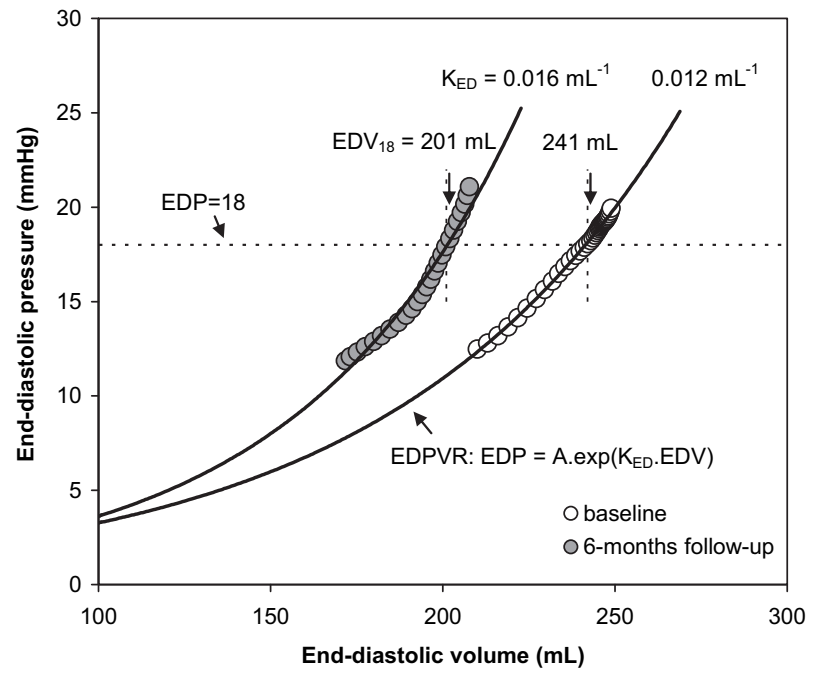

FIGURE 2. Typical examples of end-diastolic pressure-volume relationships $(E D P V R)$ at baseline and 6 months after surgical ventricular restoration (SVR) illustrating increased diastolic stiffness constant $\left(K_{E D}\right)$ and reduced $\mathrm{LV}$ volume. EDPVR intercepts at $18 \mathrm{~mm} \mathrm{Hg}\left(E D V_{18}\right)$ are indicated. $E D P$, End-diastolic pressure; $E D V$, end-diastolic volume. 
(Figure 2). Further research is needed to investigate this issue and whether patients who are prone to the development of diastolic dysfunction should be excluded or whether modifications in the procedure such as an adaptation of the target cavity volume should be considered. However, considering the positive net effect of the surgical procedure on improved clinical outcome, it is clear that the effect of SVR on systolic function, dyssynchrony, and wall stress is more prominent than the possible adverse effect on diastolic function.

\section{References}

1. Athanasuleas CL, Buckberg GD, Stanley AW, Siler W, Dor V, Di Donato M, et al. Surgical ventricular restoration in the treatment of congestive heart failure due to post-infarction ventricular dilation. J Am Coll Cardiol. 2004;44:1439-45.

2. Menicanti L, Castelvecchio S, Ranucci M, Frigiola A, Santambrogio C, de Vincentiis C, et al. Surgical therapy for ischemic heart failure: single-center experience with surgical anterior ventricular restoration. J Thorac Cardiovasc Surg. 2007;134:433-41.

3. Jones RH, Velazquez EJ, Michler RE, Sopko G, Oh JK, O'Connor CM, et al. Coronary bypass surgery with or without surgical ventricular reconstruction. $N$ Engl J Med. 2009;360:1705-17.

4. Maxey TS, Reece TB, Ellman PI, Butler PD, Kern JA, Tribble CG, et al. Coronary artery bypass with ventricular restoration is superior to coronary artery bypass alone in patients with ischemic cardiomyopathy. J Thorac Cardiovasc Surg. 2004;127:428-34.

5. Mehra MR, Reyes P, Benitez RM, Zimrin D, Gammie JS. Surgery for severe mitral regurgitation and left ventricular failure: what do we really know? J Card Fail. 2008; 14:145-50.

6. Tulner SA, Steendijk P, Klautz RJ, Bax JJ, Schalij MJ, van der Wall EE, et al. Surgical ventricular restoration in patients with ischemic dilated cardiomyopathy: evaluation of systolic and diastolic ventricular function, wall stress, dyssynchrony, and mechanical efficiency by pressure-volume loops. J Thorac Cardiovasc Surg. 2006;132:610-20.

7. Dor V, Saab M, Coste P, Kornaszewska M, Montiglio F. Left ventricular aneurysm: a new surgical approach. Thorac Cardiovasc Surg. 1989;37:11-9.

8. Nozawa T, Yasumura Y, Futaki S, Tanaka N, Uenishi M, Suga H. Efficiency of energy transfer from pressure-volume area to external mechanical work increases with contractile state and decreases with afterload in the left ventricle of the anesthetized closed-chest dog. Circulation. 1988;77:1116-24.

9. Arts T, Bovendeerd PH, Prinzen FW, Reneman RS. Relation between left ventricular cavity pressure and volume and systolic fiber stress and strain in the wall. $B i$ ophys J. 1991;59:93-102.

10. ten Brinke EA, Klautz RJ, Tulner SA, Engbers FH, Verwey HF, Atsma DE, et al. Haemodynamics and left ventricular function in heart failure patients: comparison of awake versus intra-operative conditions. Eur J Heart Fail. 2008;10:467-74.

11. Lee WS, Huang WP, Yu WC, Chiou KR, Ding PY, Chen CH. Estimation of preload recruitable stroke work relationship by a single-beat technique in humans. Am J Physiol Heart Circ Physiol. 2003;284:H744-50.

12. Steendijk P, Tulner SA, Schreuder JJ, Bax JJ, van Erven L, van der Wall EE, et al. Quantification of left ventricular mechanical dyssynchrony by conductance catheter in heart failure patients. Am J Physiol Heart Circ Physiol. 2004;286:H723-30.

13. Cirillo M, Amaducci A, Villa E, Tomba MD, Brunelli F, Mhagna Z, et al. A new shape for an old function: lasting effect of a physiologic surgical restoration of the left ventricle. J Cardiothorac Surg. 2006;1:40.

14. Qin JX, Shiota T, McCarthy PM, Asher CR, Hail M, Agler DA, et al. Importance of mitral valve repair associated with left ventricular reconstruction for patients with ischemic cardiomyopathy: a real-time three-dimensional echocardiographic study. Circulation. 2003;108(Suppl 1):II241-6.
15. Di Donato M, Sabatier M, Dor V, Gensini GF, Toso A, Maioli M, et al. Effects of the Dor procedure on left ventricular dimension and shape and geometric correlates of mitral regurgitation one year after surgery. J Thorac Cardiovasc Surg. 2001;121:91-6.

16. Fantini F, Barletta G, Toso A, Baroni M, Di Donato M, Sabatier M, et al. Effects of reconstructive surgery for left ventricular anterior aneurysm on ventriculoarterial coupling. Heart. 1999;81:171-6.

17. Di Donato M, Castelvecchio S, Kukulski T, Bussadori C, Giacomazzi F, Frigiola A, et al. Surgical ventricular restoration: left ventricular shape influence on cardiac function, clinical status, and survival. Ann Thorac Surg. 2009;87: 455-61.

18. Dor V, Civaia F, Alexandrescu C, Montiglio F. The post-myocardial infarction scarred ventricle and congestive heart failure: the preeminence of magnetic resonance imaging for preoperative, intraoperative, and postoperative assessment. J Thorac Cardiovasc Surg. 2008;136:1405-12.

19. Suma H, Tanabe H, Uejima T, Isomura T, Horii T. Surgical ventricular restoration combined with mitral valve procedure for endstage ischemic cardiomyopathy. Eur J Cardiothorac Surg. 2009;36:280-4; discussion 284-5.

20. Steendijk P, Baan J Jr, van der Velde ET, Baan J. Effects of critical coronary stenosis on global systolic left ventricular function quantified by pressure-volume relations during dobutamine stress in the canine heart. J Am Coll Cardiol. 1998;32:816-26.

21. Buckberg G, Hoffman JI, Mahajan A, Saleh S, Coghlan C. Cardiac mechanics revisited: the relationship of cardiac architecture to ventricular function. Circulation. 2008;118:2571-87.

22. Kasner M, Westermann D, Steendijk P, Gaub R, Wilkenshoff U, Weitmann K, et al. Utility of Doppler echocardiography and tissue Doppler imaging in the estimation of diastolic function in heart failure with normal ejection fraction: a comparative Doppler-conductance catheterization study. Circulation. 2007; 116:637-47.

23. Steendijk P, Meliga E, Valgimigli M, Ten Cate FJ, Serruys PW. Acute effects of alcohol septal ablation on systolic and diastolic left ventricular function in patients with hypertrophic obstructive cardiomyopathy. Heart. 2008;94:1318-22.

24. Zhang P, Guccione JM, Nicholas SI, Walker JC, Crawford PC, Shamal A, et al. Left ventricular volume and function after endoventricular patch plasty for dyskinetic anteroapical left ventricular aneurysm in sheep. J Thorac Cardiovasc Surg. 2005; 130:1032-8

25. Castelvecchio S, Menicanti L, Ranucci M, Di Donato M. Impact of surgical ventricular restoration on diastolic function: implications of shape and residual ventricular size. Ann Thorac Surg. 2008;86:1849-54.

26. Dardas PS, Pitsis AA, Mezilis NE, Tsikaderis DD, Ninios VN, Boudoulas H. Left atrial function and work after surgical ventricular restoration in postmyocardial infarction heart failure. J Am Soc Echocardiogr. 2008;21:841-7.

27. Westermann D, Kasner M, Steendijk P, Spillmann F, Riad A, Weitmann K, et al. Role of left ventricular stiffness in heart failure with normal ejection fraction. Circulation. 2008;117:2051-60.

28. Eagle KA, Guyton RA, Davidoff R, Edwards FH, Ewy GA, Gardner TJ, et al. ACC/AHA 2004 guideline update for coronary artery bypass graft surgery: a report of the American College of Cardiology/American Heart Association Task Force on Practice Guidelines (Committee to Update the 1999 Guidelines for Coronary Artery Bypass Graft Surgery). Circulation. 2004;110:e340-437.

29. Buckberg GD, Athanasuleas CL. The STICH trial: misguided conclusions. J Thorac Cardiovasc Surg. 2009;138:1060-4.

30. Bax JJ, Braun J, Somer ST, Klautz R, Holman ER, Versteegh MI, et al. Restrictive annuloplasty and coronary revascularization in ischemic mitral regurgitation results in reverse left ventricular remodeling. Circulation. 2004;(11 Suppl 1): 110:II103-8.

31. Fattouch K, Guccione F, Sampognaro R, Panzarella G, Corrado E, Navarra E, et al. POINT: Efficacy of adding mitral valve restrictive annuloplasty to coronary artery bypass grafting in patients with moderate ischemic mitral valve regurgitation: a randomized trial. J Thorac Cardiovasc Surg. 2009;138: $278-85$. 